\title{
An eigenvalue study of the MLC circuit
}

\section{Lindberg, Erik; Murali, K.}

\section{Published in:}

Electronics, Circuits and Systems, 1998 IEEE International Conference on

Link to article, DOI:

10.1109/ICECS.1998.814935

Publication date:

1998

\section{Document Version}

Publisher's PDF, also known as Version of record

Link back to DTU Orbit

Citation (APA):

Lindberg, E., \& Murali, K. (1998). An eigenvalue study of the MLC circuit. In Electronics, Circuits and Systems, 1998 IEEE International Conference on (Vol. 2, pp. 521-524). IEEE. https://doi.org/10.1109/ICECS.1998.814935

\section{General rights}

Copyright and moral rights for the publications made accessible in the public portal are retained by the authors and/or other copyright owners and it is a condition of accessing publications that users recognise and abide by the legal requirements associated with these rights.

- Users may download and print one copy of any publication from the public portal for the purpose of private study or research.

- You may not further distribute the material or use it for any profit-making activity or commercial gain

- You may freely distribute the URL identifying the publication in the public portal

If you believe that this document breaches copyright please contact us providing details, and we will remove access to the work immediately and investigate your claim. 


\title{
An eigenvalue study of the MLC circuit.
}

\author{
E. Lindberg and K. Murali \\ Dpt. Information Technology, 344 Technical University of Denmark \\ DK-2800 Lyngby, Denmark \\ Phone (+45) 4525 3650, fax (+45) 4588 0117, e-mail el@it.dtu.dk
}

\begin{abstract}
The MLC circuit is the simplest non-autonomous chaotic circuit $[01,02,03]$. Insight in the behaviour of the circuit is obtained by means of a study of the eigenvalues of the linearized Jacobian of the non-linear differential equations [04]. The trajectories of the eigenvalues as functions of the parallel loss conductance are found. An explanation of the chaotic behaviour based on the behaviour of the autonomous system is given.
\end{abstract}

\section{Introduction}

The Murali-Lakshmanan-Chua circuit is composed of (a coil $L$ with a series loss resistor $R_{s}$ ) in parallel with (a capacitor $\mathrm{C}$ with a nonlinear parallel loss conductor $\mathrm{G}_{\mathrm{p}}$ ) (Fig.1).

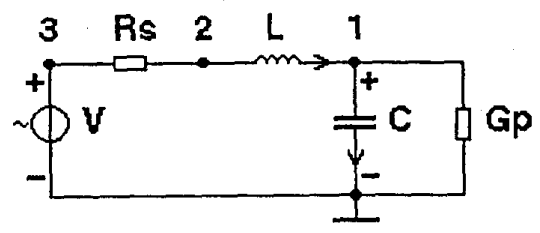

Fig. 1, The Murali-Lakshmanan-Chua circuit

The nonlinear loss conductor $G_{p}$ may be realized by means of Chua's diode [05] (Fig. 2). By inserting an independent sinusoidal voltage source $\mathrm{V}$ in series with $\mathrm{L}$ and $R_{s}$ chaos may be observed.

Because of only one nonlinear component $G_{p}$ the trajectories of the eigenvalues of the linearized Jacobian of the nonlinear differential equations may be found by means of simple linear frequency analysis varying the dynamic value of $G_{p}$, gnl, in a specific case where $L=$ $18 \mathrm{mH}, \mathrm{R}_{\mathrm{s}}=1340 \Omega, \mathrm{C}=10 \mathrm{nF}$. The dynamic value, gnl, of the nonlinear parallel conductor $G_{p}$ is varied from $-1 e+19$ to $+1 e+18$.

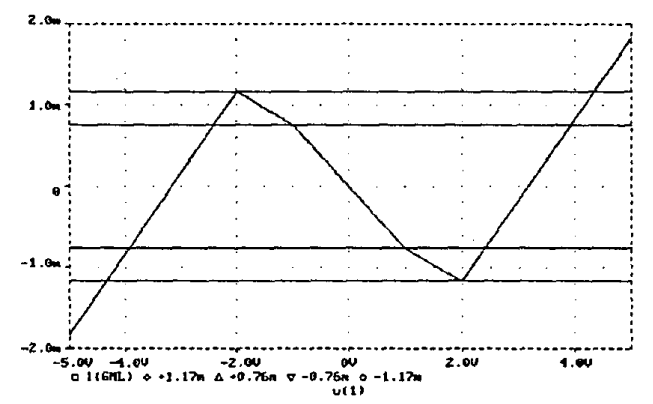

Fig. 2, The Chua diode characteristic, $i=f(v)$

\section{Qualitative analysis}

When the dynamic parallel loss conductance gnl is very large and positive the coupling between the coil $\mathrm{L}$ and the capacitor $C$ is very small. The voltages and currents will become exponentially damped signals. The energy in connection with the coil L (the magnetic flux) will be transformed into heat in the resistor $R_{b}$ with the time constant $\tau_{\mathrm{L}}=\mathrm{L} / \mathrm{R}_{\mathrm{q}}$ and the energy in connection with the capacitor $C$ (the electric charge) will be transformed into heat in the conductor $G_{p}$ with the time constant $\tau_{c}$ $=\mathrm{C} / \mathrm{G}_{\mathrm{p}}$. This behaviour corresponds to two real poles $s=p_{1}=-R_{s} / L$ from the impedance $Z_{L}=R_{s}+s * L$ and $s=p_{2}=-G_{p} / C$ from the admittance $Y_{c}=G_{p}+$ $\mathrm{s} * \mathrm{C}$.

When gnl is very large and negative the signals will be exponentially increasing signals with the time constants mentioned above.

When the dynamic parallel loss conductance gnl is zero the circuit is a simple LC oscillator with series losses and the voltages and currents will be damped sinusoids. The circuit is a second order circuit. The eigenvalues of 
the linearized Jacobian are either two real poles or a pair of complex poles in the complex frequency plane. It is to be expected that the complex pair of poles will follow a trajectory which goes from one point to another on the real axis. The two points corresponds to two real double poles. The poles are the roots of the characteristic polynomial of the second order differential equation modelling the system:

$$
\begin{gathered}
s^{2}+(2 \alpha) s+\omega_{0}{ }^{2} \\
\text { where } 2 \alpha=\left(\frac{G_{p}}{C}+\frac{R_{s}}{L}\right) \text { and } \omega_{0}{ }^{2}=\frac{1+R_{s} G_{p}}{L C}
\end{gathered}
$$

The roots are:

$$
p_{1}, p_{2}=-\alpha \pm \sqrt{\alpha^{2}-\omega_{0}^{2}}
$$

For $\omega_{0}^{2}>\alpha^{2}$ the roots become a pair of complex poles:

$$
\mathrm{p}_{1}, \mathrm{p}_{2}=-\alpha \pm j \sqrt{\omega_{0}^{2}-\alpha^{2}} .
$$

For $\omega_{0}{ }^{2}=\alpha^{2}$ the roots become a pair of real double roots. The corresponding values of $G_{p}$ becomes:

$$
G_{p}=C\left(\frac{R_{s}}{L} \pm \frac{2}{\sqrt{L C}}\right)=\frac{C}{\tau_{L}} \pm 2 \sqrt{\frac{C}{L}}
$$

\section{Quantitative Analysis.}

By means of the formulas above Table 1 below is calculated for a specific set of parameters $L=18 \mathrm{mH}$, $\mathrm{R}_{\mathrm{s}}=1340 \Omega$ and $\mathrm{C}=10 \mathrm{nF}$.

\begin{tabular}{||l|l|l||}
\hline $\mathrm{G}_{p}$ & $\mathrm{re} 1 / \mathrm{re}$ & $\mathrm{re} / \mathrm{im}$ \\
\hline$-\mathrm{le}+19$ & $+1 \mathrm{e}+27$ & $-74.444444 \mathrm{e}+3$ \\
\hline$-0.760000 \mathrm{e}-3$ & $+10.918193 \mathrm{e}+3$ & $-9.362627 \mathrm{e}+3$ \\
\hline$-0.74626760 \mathrm{e}-3$ & +112.21 & +70.11 \\
\hline$-0.74626754 \mathrm{e}-3$ & +91.15 & +91.15 \\
\hline$-0.74626750 \mathrm{e}-3$ & +91.15 & $\pm \mathrm{j} 17.39$ \\
\hline$-0.41000000 \mathrm{e}-3$ & $-16.7222222 \mathrm{e}+3$ & $\pm \mathrm{j} 47.15613 \mathrm{e}+3$ \\
\hline 0 & $-37.2222222 \mathrm{e}+3$ & $\pm \mathrm{j} 64.57602 \mathrm{e}+3$ \\
\hline$+2.23515640 \mathrm{e}-3$ & $-148.980042 \mathrm{e}+3$ & $\pm \mathrm{j} 14.81$ \\
\hline$+2.23515643 \mathrm{e}-3$ & $-148.980044 \mathrm{e}+3$ & $-148.980043 \mathrm{e}+3$ \\
\hline$+2.23515650 \mathrm{e}-3$ & $-149.900298 \mathrm{e}+3$ & $-148.957115 \mathrm{e}+3$ \\
\hline+1 & $-99.999944 \mathrm{e}+6$ & $-74.500041 \mathrm{e}+3$ \\
\hline$+1 \mathrm{e}+18$ & $-1 \mathrm{e}+26$ & $-74.444444 \mathrm{e}+3$ \\
\hline
\end{tabular}

Table 1 Eigenvalues as functions of $G_{p}$

It is seen that for $G_{p}=-0.74626754 e-3$ the real double pole $s=+91.15$ is in the right half plane. For $G_{p}$ going to "minus infinite" the real pole rel corresponding to the capacitor goes to "plus infinite" and the real pole re2 corresponding to the coil goes to $-74.444 \mathrm{e}+3$. Due to the maximum slope of $-0.76 \mathrm{mS}$ for $G_{p}$ in origo the maximum value for re 1 becomes $+10.92 \mathrm{e}+3$. Due to this large real pole it is obvious that the autonomous system has an unstable point of balance in origo. Even very small initial conditions close to origo will give rise to exponentially increasing signals in positive or negative direction. If the autonomous system is started up with an initial condition of e.g. 1e-12 volt across the capacitor $C$ the signals will increase exponentially until the bending point of the piecewise linear conductance $G_{p}$, i.e. it is to be expected that the voltage of $\mathrm{C}$ will rise to 1 volt when the complex pole pair for $\mathrm{G}_{\mathrm{p}}=-0.41 \mathrm{mS}, \mathrm{s}=-16.72 \mathrm{e}+3 \pm \mathrm{j} * 47.16 \mathrm{e}+3$, will take over and give rise to a damped oscillation. This behaviour is shown in Fig. 3 where the currents in the nonlinear conductance and the capacitor are shown as functions of time and of the voltage across.

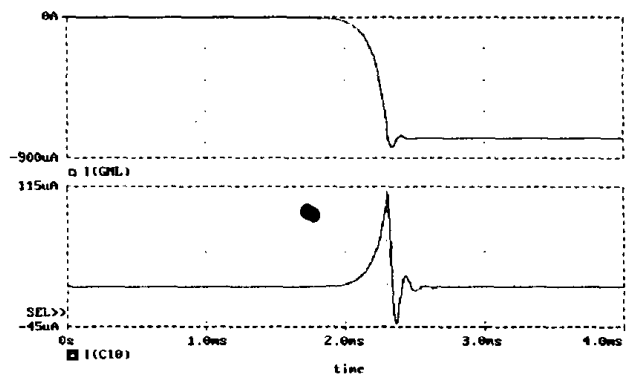

Fig.3a, Autonomous system performance. $\mathrm{i}(\mathrm{gnl})$ and $\mathrm{i}(\mathrm{C} 10)$ as functions of time

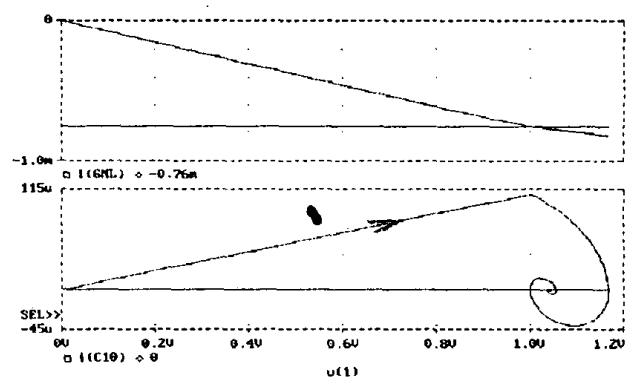

Fig.3b, Autonomous system performance. $\mathrm{i}(\mathrm{gnl})$ and $\mathrm{i}(\mathrm{C} 10)$ as functions of $\mathrm{V}(1)$

The trajectories of the eigenvalues are shown in the figures 4,5 and 6 . The dynamic value of the parallel conductance $G_{p}$, gnl, is varied from $-1 e+19$ Siemens to $+1 \mathrm{e}+18$ Siemens. In Fig. 4 it is seen how the complex pole pair leaves the real axis for $\mathrm{gnl}=-0.746 \mathrm{mS}$ and 


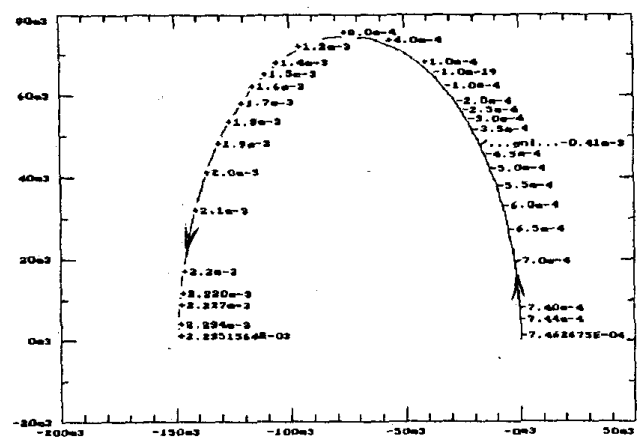

Fig. 4, Complex pole pair trajectory.

Positive imaginary part as function of real part.

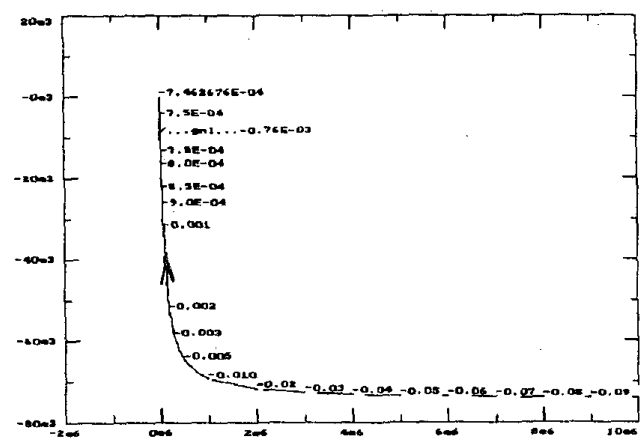

Fig. 5, Real poles "trajectory" for negative values of gnl.

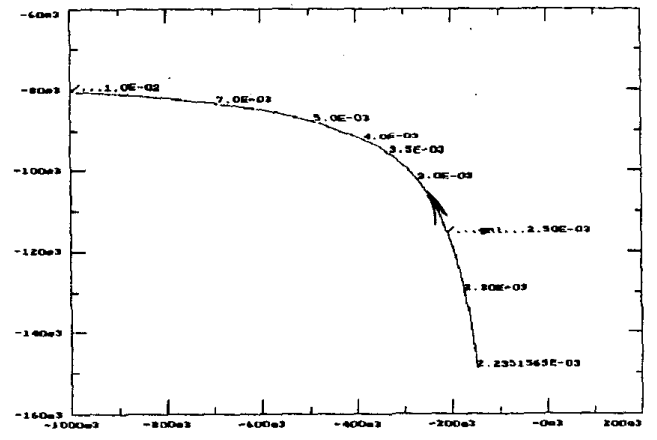

Fig. 6, Real poles "trajectory" for positive values of gnl.

returns back to the real axis for $\mathrm{gnl}=+2.235 \mathrm{mS}$. The trajectory of the complex pole pair crosses the imaginary axis for $\mathrm{gnl}=-0.7444445 \mathrm{E}-03$ where the real part of the complex pole becomes zero and the imaginary part becomes +3685.082000 rps corresponding to the frequency $586.4990160 \mathrm{~Hz}$. In Fig. 5 the two real poles are pictured against each other for negative values of gnl. It is seen how the pole in connection with the coil goes to $-74.4 \mathrm{e}+3$ while the pole related to the capacitor goes to

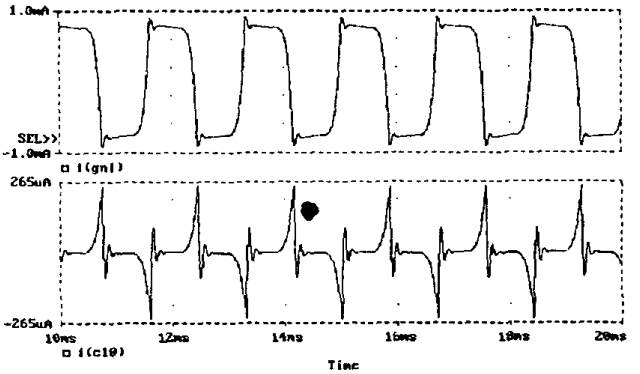

Fig. 7a, $i(g n l)$ and $i(C 10)$ as functions of time. Voltage source $\mathrm{V}$ :

Amplitude $=25 \mathrm{mV}$, Frequency $=586.499016 \mathrm{~Hz}$

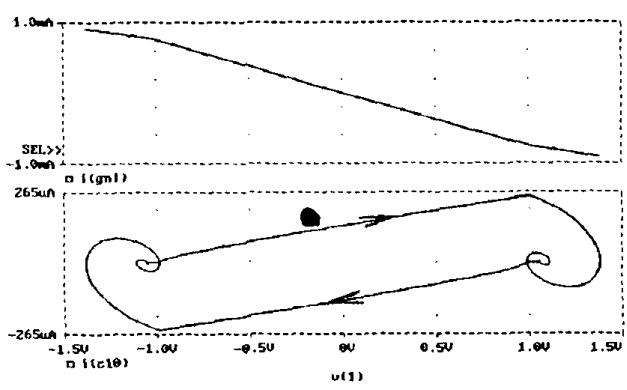

Fig. $7 \mathrm{~b}$, i(gnl) and $\mathrm{i}(\mathrm{C} 10)$ as functions of $\mathrm{V}(1)$ Voltage source $\mathrm{V}$ :

Amplitude $=25 \mathrm{mV}$, Frequency $=586.4990160 \mathrm{~Hz}$

"plus infinite". In Fig. 6 the two real poles are pictured against each other for positive values of gnl. It is seen how the pole in connection with the capacitor goes to "minus infinite" while the pole related to the coil goes to $-74.4 \mathrm{e}+3$.

\section{Limit Cycle and Chaotic Behaviour.}

With knowledge about the eigenvalues of the system we may choose the frequency of the excitation deliberately in order to obtain limit cycle or chaotic behaviour when varying the amplitude of the independent voltage source. In the following PSpice with RELTOL $=1 \mathrm{e}-6$ is used for the simulations. In Fig. 7 and Fig. 8 the frequency $586.4990160 \mathrm{~Hz}$ corresponding to the point where the trajectory crosses the imaginary axis is chosen. For an amplitude of $25 \mathrm{mV}$ (Fig. 7) it is seen how the currents $\mathrm{i}(\mathrm{gnl})$ and $\mathrm{i}(\mathrm{C} 10)$ are the same as in the autonomous case (Fig. 3). Due to the varying input voltage a train of pulses is obtained. Every time the current in the capacitor $\mathrm{i}(\mathrm{ClO})$ becomes zero due to the pair of complex poles in the left halfplane the independent voltage source $V$ will bring the circuit in a situation where the real pole in the right half plane occurs and a new pulse going to the other breaking point starts up. 


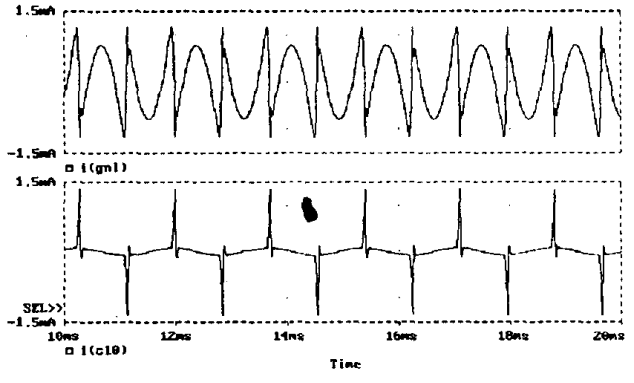

Fig. 8a, $\mathrm{i}(\mathrm{gnl})$ and $\mathrm{i}(\mathrm{C} 10)$ as funtions of time. Voltage source $\mathrm{V}$ :

Amplitude $=5 \mathrm{~V}$, Frequency $=586.4990160 \mathrm{~Hz}$

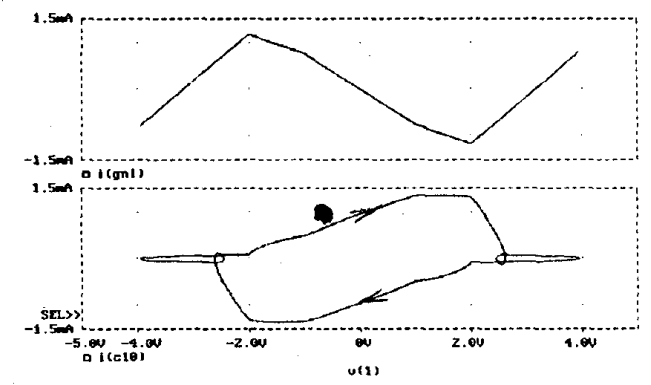

Fig. 8 b, i(gnl) and $\mathrm{i}(\mathrm{C} 10)$ as functions of $\mathrm{V}(1)$

Voltage source $\mathrm{V}$ :

Amplitude $=5 \mathrm{~V}$, Frequency $=586.4990160 \mathrm{~Hz}$

In Fig. 8 the amplitude of the independent voltage source is increased to $5 \mathrm{~V}$. It is seen how the damping of the current pulses in the capacitor becomes faster due to entering the areas with $\mathrm{gnl}=+1 \mathrm{mS}$.

In the following the frequency is chosen to $7505.13 \mathrm{~Hz}$ corresponding to $\mathrm{gnl}=-0.41 \mathrm{mS}$. If the amplitude of the independent voltage source is $25 \mathrm{mV}$ a first order limitcycle at one of the bending points is obtained. With increasing amplitude of $\mathrm{V}$ limit cycle and chaotic behaviour may be observed. For an amplitude of $54.9 \mathrm{mV}$ chaos around one of the bending points is found. For $55.00 \mathrm{mV}$ both bending points are involved in chaotic behaviour. For a time range of about $20 \mathrm{~ms}$ chaos is around one bending point and then it changes to the other bending point for some time. At $55.50 \mathrm{mV}$ the intervals with chaos around one bending point becomes smaller. At $56.5 \mathrm{mV}$ we see a 3 'rd order limit cycle around one of the bending points. In Fig. 9 the amplitude of $\mathrm{V}$ is $60 \mathrm{mV}$ and chaos including both bending points occur. At $100 \mathrm{mV}$ and $1 \mathrm{~V} 1$ 'st order limit cycles occur. For amplitude $1 \mathrm{~V}$ it becomes necessary to change RELTOL to $1 \mathrm{e}-5$ in PSpice in order to avoid problems with too small integration steps.

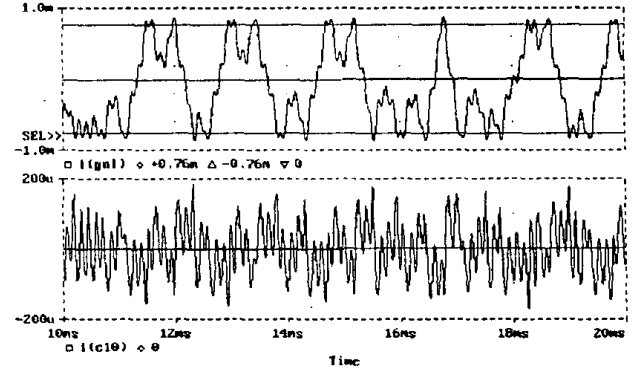

Fig. 9a, $\mathrm{i}(\mathrm{gnl})$ and $\mathrm{i}(\mathrm{C} 10)$ as functions of time. Voltage source $\mathrm{V}$ :

Amplitude $=60 \mathrm{mV}$, Frequency $=7505.13 \mathrm{~Hz}$

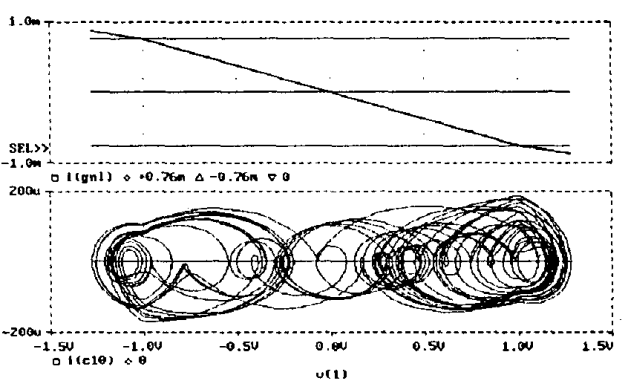

Fig. 9b, $\mathrm{i}(\mathrm{gnl})$ and $\mathrm{i}(\mathrm{C} 10)$ as functions of $\mathrm{V}(1)$. Voltage source $\mathrm{V}$ :

Amplitude $=60 \mathrm{mV}$, Frequency $=7505.13 \mathrm{~Hz}$

\section{Conclusion.}

The behaviour of the Murali-Lakshmanan-Chua circuit (MLC circuit) is investigated by means of a study of the eigenvalues of the linearized Jacobian of the non-liner differential equations. It is found that the autonomous circuit has an unstable point of balance in origo which give rise to chaotic behaviour in case of the non-autonomous circuit.

\section{References}

[01] K. Murali, M. Lakshmanan and L.O. Chua, "The Simplest Dissipative Nonautonomous Chaotic Circuit", IEEE Transactions on Circuits and Systems - I: Fundamental Theory and Applications, Vol. 41, No. 6, June 1994, pp.462-463.

[02] M. Lakshmanan and K. Murali, "Experimental chaos from non-autonomous electronic circuits", Phil. Trans. R. Soc. Lond. A, vol. 353, 1995, pp. 33-46.

[03] M. Lakshmanan and K. Murali, "Chaos in Nonlinear Oscillators", World Scientific 1996, ISBN-981-02-2143-6, pp. $161-175$

[04] E. Lindberg, "Oscillators and Eigenvalues", Proceedings ECCTD'97, Budapest, September 1997, Vol. 1, pp. 171-176. [05] M.P. Kennedy, "Robust op amp realization of Chua's circuit", Frequenz, vol. 46, 1992, pp. 66-80. 